\title{
Aeroelastic Scaling for Flexible High Aspect Ratio Wings
}

\author{
Sezsy Yusuf*, Alessandro Pontillo ${ }^{\dagger}$, Simone Weber ${ }^{\ddagger}$, David Hayes ${ }^{\S}$, and Mudassir Lone ${ }^{\mathbb{I}}$ \\ Cranfield University, Dynamic Simulation and Control Group \\ Cranfield, Bedfordshire, United Kingdom, MK43 OAL
}

\begin{abstract}
This paper provides an overview of the work conducted as part of the Cranfield BEAm Reduction and Dynamic Scaling (BEARDS ) programme, which aims to develop a methodology for designing, manufacturing and testing of a dynamically scaled High Aspect Ratio (HAR) Wing inside Cranfield 8' $x 6$ ' wind tunnel. The aim of this paper is to develop a methodology that adopts scaling laws to allow experimental testing of a conceptual flexible-wing planform as part of the design process. Based on the Buckingham $\pi$ theorem, a set of scaling laws are determined that enable the relationship between a full-scale and sub-scale model. The dynamically sub-scaled model is manufactured as a combination of spar, skin, and added mass representing the stiffness, aerodynamic profile, and aeroelastic behaviour respectively. The spar was manufactured as a cross-sectional shape using Aluminium material, while the skin was manufactured using PolyJet technology. Compromises due to the manufacturing process are outlined and lessons learned during the development of the sub-scaled model are highlighted.
\end{abstract}

\section{Introduction}

In the past, sub-scale models have been used extensively for wind tunnel testing to understand its physical phenomena and simultaneously enable a designer to predict and analyse the characteristics of a vehicle [1]. Despite the rapid advancement in computational capabilities, wind tunnel testing has still held a significant impact on aircraft validation [2]. Current practice shows that wind tunnel models are built only for a specific discipline by applying different scaling laws depending on the area of interest, such as for aerodynamic, flight dynamic, or aeroelastic analyses. However, the trend in the aerospace design shifts towards a more integrated concept [3] requiring a close link between each discipline. This is especially important for a high aspect ratio wing that brings the aeroelastic frequency closer to the frequency of the rigid-body dynamics [4].

A recent study using Cranfield Accelerated Aeroplanes Loads Model (CA ${ }^{2} \mathrm{LM}$ ) framework [5] was conducted to observe lateral manoeuvre of an aircraft with a rigid and flexible wing structure. This study shows that introducing flexibility changes the identified stability and control derivatives of the particular aircraft [6]. This emphasises the need for a more comprehensive aeroelastic wind tunnel test that combines aerodynamics, flight dynamics, and structural dynamics simultaneously. For this reason, the BEAm Reduction and Dynamic Scaling (BEARDS ) programme was started to develop a process for the designing, manufacturing and testing of a dynamically scaled High Aspect Ratio (HAR) wing including control surfaces (spoilers and aileron) and possibly folding wing tips. The wing design was scaled according to the physical properties of Cranfield's 8" x 6" tunnel. Designing an aeroelastic scaled model has been elaborated in a variety of studies [7-[13]. Heeg et al [13] developed a methodology to map a full scale to a sub-scaled model for a static wind tunnel test, while Ricciardi [9, 10] derived a non-dimensional aeroelastic equation of motion for aeroelastic scale design. Furthermore, Wan and Cesnik [7] emphasised that linear scaling laws are applicable for a non-linear aeroelastic model. The consequence of applying scaling laws is that the sub-scale model cannot be manufactured using the same material properties as the full-size aircraft, which emphasises the need for re-designing the internal structure of the sub-scale model. Ricciardi used the ladder configuration [10] while Zhu et al [14] used a 3-D printed technology to design a scaled wing-box.

For a high aspect ratio scaled wing, Spada [12] suggested the rib and spar design with balsa wood as the skin cover. However, these methods bring some disadvantages, such as buckling of the skin due to high deflection [15], which consequently changes the aerodynamic profile. One of the solutions to the buckling is by building the aerodynamic

\footnotetext{
*PhD researcher, Dynamic Simulation and Control Group, sezsy.yusuf@cranfield.ac.uk

$\dagger \mathrm{PhD}$ researcher, Dynamic Simulation and Control Group, a.pontillo@ cranfield.ac.uk

${ }^{\ddagger}$ PhD researcher, Dynamic Simulation and Control Group, s.weber@cranfield.ac.uk

${ }^{\S} \mathrm{PhD}$ researcher, Dynamic Simulation and Control Group, d.hayes@cranfield.ac.uk

IILecturer, School of Aerospace, Transport and Manufacturing, m.m.lone@cranfield.ac.uk
} 
profile into several sections and leave a small gap between each section. This results in alteration of the airflow, which could lead and increase drag or/and a reduce the lift force. Because of these implications, BEARDS makes use of a different manufacturing methodology. The skin adopts the PolyJet technology that allows printing of multi-materials continuously along the span [15]. BEARDS is applying this technology by printing rigid and elastic parts repeatedly. By doing so, the BEARDS skin adds negligible stiffness to the spar while at the same time allows the model to bend without any buckling issue. As PolyJet technology is relatively new in this area, BEARDS was planned as a two-phase programme (see Fig 1a) [15]. Phase 1 (XB-1) has been conducted to assess the risk of using the modular design and manufacturing using PolyJet technology while at the same time testing an off-the-shelf in-house built instrumentation system [15].

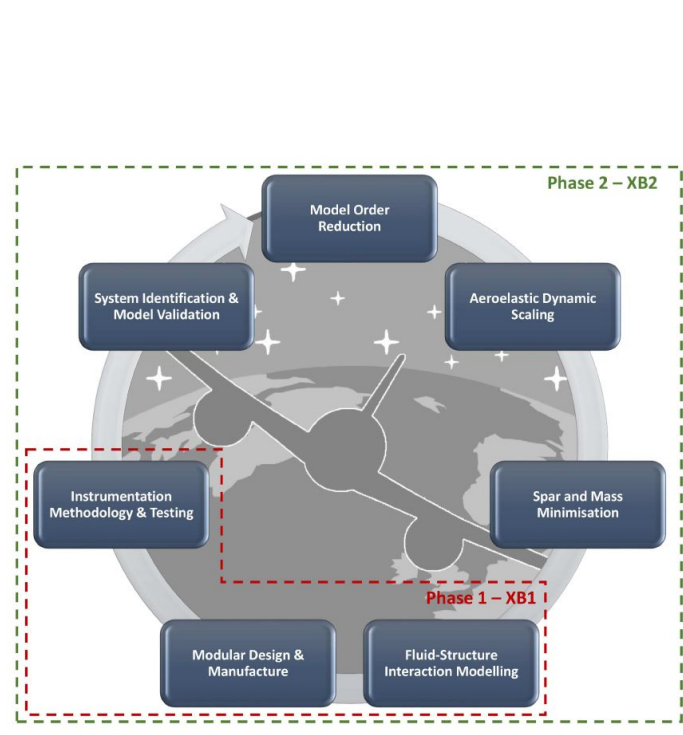

(a) GeneralBEARDS work flow

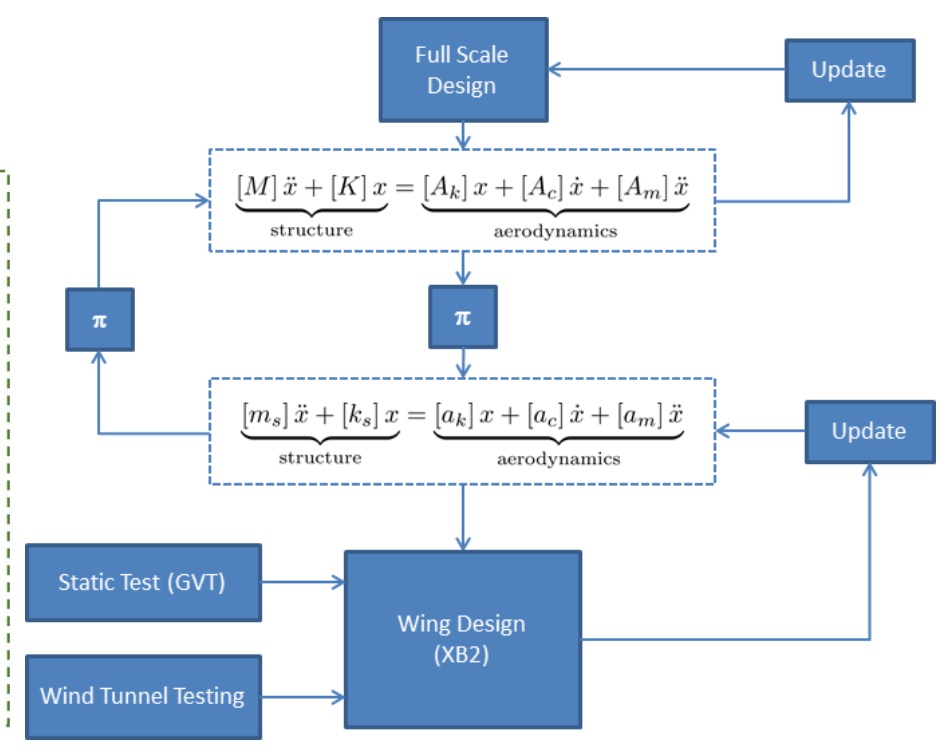

(b) XB-2 work flow

Fig. 1 Work flow

The work flow of XB-2 (see Fig $1 \mathrm{~b}$ ) starts with the definition of a full-scale wing design. Based on Timoshenko beam bending theory, a reduced order structural model for the full-scale model is defined, followed by the definition of the sub-scale model based on the aeroelastic scaling laws. Based on the scaling laws, an optimisation problem is solved to match the characteristics of the sub-scale model to define its physical properties. At the same time, an in-house software called BEARDS Theoretical Model $\left(\mathrm{BEaRDS}^{T M}\right)$ was developed to predict the fluid-structure interaction and to compare the aeroelastic response of the full-scale with the sub-scale model. After the sub-scale model was manufactured, a series of ground vibration tests (GVT) were conducted to identify the structural characteristics of the physical model, followed by wind tunnel tests to evaluate the aeroelastic behaviour of the sub-scale model. System identification methods will be used to characterise the dynamic behaviour of the sub-scale model. Data sets obtained from both GVT and wind tunnel test will then be used to update the theoretical model, and evaluate the full-scale model.

The aim of this paper is to develop a methodology that adopts scaling laws to allow experimental testing of a conceptual flexible-wing planform as part of the design process. The motivation for developing such scaled model is 1) to minimise the potential problems that require design loop during the detail design process, 2) to maximise information regarding dynamic behaviour due to flexibility effect as early as possible, and 3) maturing the design of a high aspect ratio wing. This paper is structured such that the full-scale model design and dynamic scaling methodology is explained briefly in the theoretical background at Section II, which forms the foundation for the development of the sub-scale model in Section III. Section III emphasises the learning curve of utilising PolyJet technology for a scaled high aspect ratio wing. In Section IV, the comparison between theoretical and experimental results are elaborated for the sub-scale spar configuration. Finally, conclusions and further work are presented in Section V. 


\section{Theoretical Background}

\section{A. Full Scale Aircraft Model}

The XB-2 aircraft is a conceptual design that uses a high aspect ratio wing similar to the Airbus A320 class. The wing was designed to have minimum exergy destruction at cruise conditions $(190 \mathrm{~m} / \mathrm{s}$ at $35,000 \mathrm{ft})[16]$. For a detailed explanation of the XB-2 aircraft design, the reader is referred to Ref.[16]. The work in this paper only considers the half-span wing for scaling. The half-wing design is presented in Fig 2

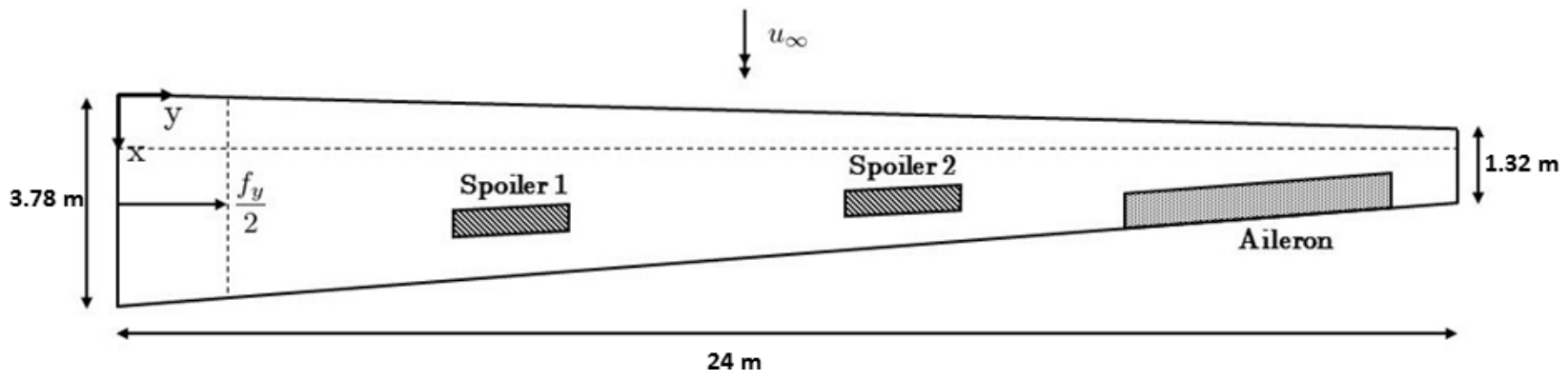

Fig. 2 BEARDS (XB2) full scale design

The XB-2 wing is a simple and idealistic high aspect ratio wing with $0^{\circ}$ sweep angle at $25 \%$ of the chord, aspect ratio of 18.8, and mean aerodynamic chord of 2.75 meters using NACA 23015 as the aerodynamic profile. The half-span length is 24 meters long, calculated from the centre of the fuselage. The wing is equipped with two spoilers and aileron and designed such that the elastic axis is located at around the aerodynamic centre, in order to minimise the torsional effect due to the lift force. Torenbeek gave an estimation of the total wing weight as around $12 \%$ of target maximum take-off weight (MTOW)[17]. With the aim of having a similar MTOW as Airbus A-320 (73,500 kg), the half-wing mass was estimated to be $4410 \mathrm{~kg}$ and designed as linearly distributed to target the first structural mode (bending mode) to be at around $0.7 \mathrm{~Hz}$. In theory, this first structural mode is close to the rigid body dynamics (Short Period Mode). The first structural mode is expected to appear at a lower frequency so that the coupling between the rigid body and aeroelastic dynamics can be evaluated.

Based on the wing definition, a reduced order model was developed based on Timoshenko beam element theory [18]. The structural dynamics are described using the following equation of motion:

$$
E I \frac{\partial^{4} w}{\partial y^{4}}+\rho \frac{\partial^{2} w}{\partial t^{2}}-\rho I\left(1+\frac{E}{\kappa G}\right) \frac{\partial^{4} w}{\partial y^{2} \partial t^{2}}+\frac{\rho^{2} I}{\kappa G} \frac{\partial^{4} w}{\partial t^{4}}=q(y, t)+\frac{\rho I}{\kappa A G} \frac{\partial^{2} q(y, t)}{\partial t^{2}}-\frac{E I}{\kappa A G} \frac{\partial^{2} q}{\partial y^{2}}
$$

which can be written in the well-known form introducing the general displacement $q$, and expressed in terms of mass matrix $[\mathbf{M}]$, and stiffness matrix $[\mathbf{K}]$ as:

$$
M \ddot{q}+C \dot{q}+K q=F(t)
$$

where $F$ is the external force.

\section{B. Aeroelastic Dynamic Scaling}

The equation of motion of an aeroelastic model is defined as:

$$
\underbrace{[M] \ddot{\mathbf{x}}+[K] \mathbf{x}}_{\text {structure }}=\underbrace{\left[A_{k}\right] \mathbf{x}+\left[A_{c}\right] \dot{\mathbf{x}}+\left[A_{m}\right]}_{\text {aerodynamics }} \ddot{\mathbf{x}}+\underbrace{[M] a_{g}}_{\text {gravity }}
$$

in which $\mathbf{x}$ is the state vector that represents six degree-of-freedom (DoF). The left hand side of the equation representing the structural dynamics as defined in Eqn 2. The right hand side of the equation shows the aerodynamic forces, $A_{k}$, $A_{c}$, and $A_{m}$, which are aerodynamic stiffness, damping, and mass respectively, and gravitational force with $a_{g}$ as the gravitational acceleration.

To develop the aeroelastic sub-scale model, a scaling law based on non-dimensional methodology elaborated by Ricciardi [9], which is also based on dimensional analysis [19], is utilised. The non-dimensional equation of motion in 
modal form, as derived by Ref.[9] is defined as:

$$
\langle\bar{m}\rangle \stackrel{*}{\bar{\eta}}+\left\langle\bar{m} \bar{\omega}^{2}\right\rangle \bar{\eta}=\frac{1}{2} \frac{\pi_{I}}{\pi_{\omega}^{2}}\left[\left[\overline{a_{k}}\right] \bar{\eta}+\pi_{\omega}\left[\overline{a_{c}}\right] \overline{\bar{\eta}}+\pi_{\omega}^{2}\left[\overline{a_{m}}\right] \overline{\bar{\eta}}\right]+\frac{1}{F_{r}^{2} \pi_{\omega}^{2}}[\bar{m}] \Phi^{-1} \overline{a_{g}}
$$

in which $\pi_{I}=\frac{M}{\rho b^{5}}, \pi_{\omega}=\frac{\omega b}{U}, F_{r}=\frac{V}{\sqrt{b g}}$ is the inertia ratio, reduced frequency, and Froude number respectively. The diagonal elements of $\langle\bar{m}\rangle$ is the non-dimensional modal mass, $\langle\bar{\omega}\rangle$ is the non-dimensional modal frequency, and [Ф] is the non-dimensional mode shapes matrix. These non-dimensional parameters are required to match the full scaled dynamic aeroelastic behaviour ensuring similitude scaled dynamic aeroelastic response.

\section{Sub-scale Model Design}

\section{A. Scaling Laws}

Buckingham $\pi$ theorem is utilised to define the scaling rules between the full scale and sub-scale model. The theory shows that the full model of $n$ dimensional parameters can be expressed as a product combination of $k$ measures physical quantities concerned (repeating variables), resulting in $(n-k)$ non-dimensional quantities [19]. The repeating variable, also known as the independent variable, is chosen to represent the measured physical quantities, such as mass, length, and time. In this case, the physical properties of the wind tunnel (see Table 1) determines the outcome of the scaled model design.

\begin{tabular}{lll}
\hline Test Section & $:$ & $2.4 \mathrm{~m} \times 1.8 \mathrm{~m}$ \\
Mach number & $:$ & $0.15(\max )$ \\
Flow Speed & $:$ & $5-50 \mathrm{~m} / \mathrm{s}$ \\
Reynolds number & $:$ & $3.610^{6} / \mathrm{m}$ \\
Dynamic Pressure & $:$ & up to $1.5 \mathrm{kN} / \mathrm{m} 2$ \\
Temperature & $:$ & Ambient Temperature \\
\hline
\end{tabular}

Table 1 Cranfield 8'x6' Low Speed Tunnel[20]

Therefore, the chosen independent variables are length, air density, and velocity, such that :

1) Geometrical scale is defined by considering the length of the test section. Taking into account the boundary layer of the tunnel wall, the scaled wing is expected to fit maximum $90 \%$ of the test section. Based on this consideration, the geometrical scale is $1: 16$.

2) Velocity scale is defined by matching the Froude number. As the gravitational acceleration is assumed to be constant, the velocity scale is given as square-root of the geometrical scale, resulting in a velocity scale of 1:4.

3) Air density ratio is defined by considering the ISA atmosphere for the scale model and cruise condition of the full scale model $(35,000 \mathrm{ft})$. This gives an air density ratio of 3.23:1.

The other variables, known as dependent variables, such as mass, stiffness, and frequency were derived from the above mentioned independent variables, as presented in Table 2

From the scaling laws, the parameters defining the full scale and sub-scale wing are presented in Table 3 . By considering Eqn 4, the sub-scale model was designed to match the properties defined in the left hand side of the equation while keeping the same aerodynamic shape. This is possible under the assumption that the non-dimensional aerodynamic forces and moments will be equal as long as the aerodynamic shape is consistent. This reduces the aeroelastic problem into a structural design problem, which is simply defined by the mass and stiffness matrices. Thus, this eliminates the need of $\mathrm{BEaRD}_{\mathrm{D}} S^{T M}$ at this current stage.

As mentioned in the introduction, the skin was designed using PolyJet printed technology by printing a rigid and elastic pod one after another. Previous experience with the XB-1 Phase has shown that with the use of PolyJet technology, the aerodynamic shape is consistent and the influence of the skin on the overall stiffness is less than 5\% [15]. Therefore, the same procedure was adopted in which the sub-scale model was designed as combination of spar and skin. The spar was designed to match the stiffness, while the skin was designed to hold the aerodynamic shape. On top of that, added mass will be distributed to match the total mass matrix. More detailed explanation about the design of the spar, skin and added mass placement is elaborated in the following subsection. It should be noted that in this study, the sub-scale model aims to match the first four structural modes. 


\begin{tabular}{lcccc}
\hline & & & \multicolumn{2}{c}{ Scaling Factor } \\
Dimension & Unit & & Sub-Scale & Full Scale \\
\hline Length & $L$ & $\pi_{g}$ & 1 & 16 \\
Air Density & $M L^{-3}$ & $\pi_{\rho}$ & 3.23 & 1 \\
Velocity & $L T^{-1}$ & $\pi_{U}$ & 1 & 4 \\
\hline Inertia & $M L^{2}$ & $\pi_{I}=\pi_{\rho} \pi_{g}^{5}$ & 1 & $3.25 \times 10^{5}$ \\
Structural Stiffness & $M T^{-2}$ & $\pi_{K}=\pi_{\rho} \pi_{U}^{2} \pi_{g}$ & 1 & 79.33 \\
Reduced Frequency & $T^{-} 1$ & $\pi_{\omega}=\frac{\pi_{U}}{\pi_{g}}$ & 4 & 1 \\
\hline
\end{tabular}

Table 2 Scaling laws used for designing the XB-2 sub-scale model

\begin{tabular}{|c|c|c|c|c|c|}
\hline & Parameter & Symbol & Units & XB2 & XB2 scaled \\
\hline \multirow{3}{*}{$\underbrace{}_{\mid I}$} & Cruise Altitude & $h$ & $m$ & 11,280 & 0 \\
\hline & Air Density & $\rho$ & $\frac{\mathrm{kg}}{\mathrm{m}^{3}}$ & 0.3796 & 1.225 \\
\hline & Cruise Velocity & $U$ & $\mathrm{~m} / \mathrm{s}$ & 190 & 47.5 \\
\hline \multirow{11}{*}{ 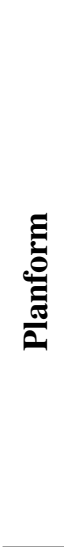 } & Aspect Ratio & AR & - & 18.8 & 18.8 \\
\hline & Semi span & $\mathrm{b}$ & $m$ & 24 & 1.5 \\
\hline & Reference area & $S_{\text {ref }}$ & $m^{2}$ & 122.4 & 0.478 \\
\hline & Sweep (LE) & $\Lambda_{\mathrm{LE}}$ & $\mathrm{rad}$ & 0.026 & 0.026 \\
\hline & Sweep $\left(\frac{c}{4}\right)$ & $\Lambda_{\frac{c}{4}}$ & $\mathrm{rad}$ & 0 & 0 \\
\hline & Root Chord & $c_{b}$ & $m$ & 3.78 & 0.236 \\
\hline & Tip Chord & $c_{t}$ & $m$ & 1.32 & 0.083 \\
\hline & Taper Ratio & $\lambda$ & - & 0.350 & 0.350 \\
\hline & MAC & $\bar{c}$ & $m$ & 2.75 & 0.172 \\
\hline & Airfoil & - & - & NACA 23015 & NACA 23015 \\
\hline & Wing Weight & $W_{w}$ & $\mathrm{~kg}$ & 4410 & 3.42 \\
\hline \multirow{4}{*}{ 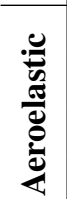 } & $1^{s t}$ Bending Freq. & $\omega_{\eta_{1}}$ & $\mathrm{~Hz}$ & 0.69 & 2.76 \\
\hline & $2^{\text {nd }}$ Bending Freq. & $\omega_{\eta_{2}}$ & $\mathrm{~Hz}$ & 3.46 & 13.78 \\
\hline & $1^{s t}$ Lagging Freq. & $\omega_{\eta_{3}}$ & $\mathrm{~Hz}$ & 3.5 & 13.9 \\
\hline & $1^{s t}$ Torsion Freq. & $\omega_{\eta_{4}}$ & $\mathrm{~Hz}$ & 6.1 & 24.26 \\
\hline
\end{tabular}

Table 3 Dimension of the XB-2 and the wind tunnel model.

\section{B. Spar Design}

Based on the scaling factors described in Table 3, the scaled stiffness matrix $K_{S}$ was defined and used to design the spar of the scaled model. This was done by matching the bending stiffness, $E I_{x x}$, and in-plane stiffness, $E I_{z z}$, of the spar with the stiffness matrix dictated by $K_{s}$. The stiffness matrix is determined using the geometrical properties, such as the area of the cross-section $A$, the distance between nodes $l$ and second moment of area $(I, J)$, as well as material properties such as shear modulus $G$ and Young's modulus $E$. The Young's modulus $E$ of the full size and scaled model are different. The full size model was designed using composite material with a Young's modulus of $5.2 \times 10^{10} \mathrm{~Pa}$, while the spar scaled model was manufactured using 6082-T6 aluminium alloy with a Young's modulus of $6.9 \times 10^{10} \mathrm{~Pa}$ to ensure a light-weight build of the spar structure. This also allowed enough weight margin for adding additional mass, such as the skin and the instrumentation system.

Considering a two-node lumped mass element as shown in Fig 3a, the mass of the element is modelled on the nodes while the stiffness is assigned to the beam connecting two nodes. In this case the diagonal matrix terms provide information of the bending and in-plane stiffness at each node. However, in the case of a multi-node beam as shown in Fig 3 b the diagonal terms, except for the first and last node, result in a coupling between the two adjacent beam elements 


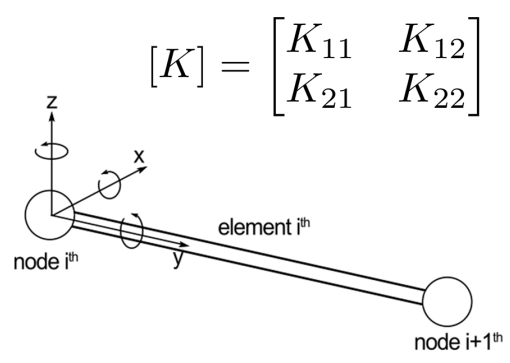

(a) Two-node beam element and reference system representation

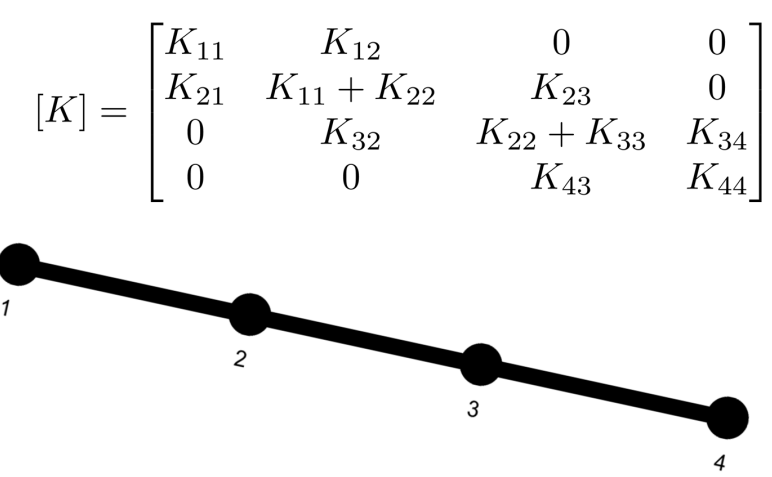

(b) Four-node beam element schematics

Fig. 3 Beam element

[21]. Therefore, the off-diagonal terms are used to read the stiffness value as it relates to the beam element in between the nodes.

To match the off-diagonal stiffness terms an optimisation routine is proposed based on the bending and in-plane stiffness $E I_{x x}$ and $E I_{z z}$. The cost function is described as follows:

$$
J=\left([E I]_{x x}^{K}-[E I]_{x x}^{s p a r}\right)^{2}+\left([E I]_{z z}^{K}-[E I]_{z z}^{s p a r}\right)^{2}
$$

where the superscript $K$ refers to the scaled stiffness matrix. The second moment of area $I$ depends on the shape of the cross section of the spar. Fig 5 shows the two cross sections initially considered for the spar design. Although the

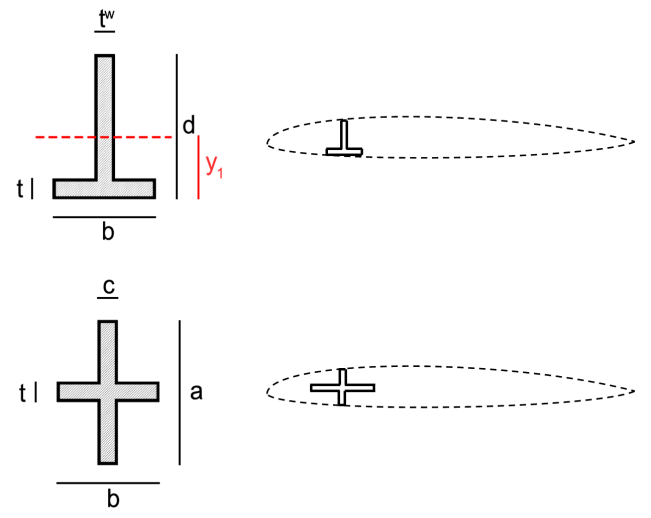

Fig. 4 Two different shapes were considered as spar cross section: (left) T-shape and (right) cross-shape. To notice that the bending axis of the T-shape section (red) does not lie on any symmetry axis of the section.

T-shape section is easier to manufacture, its asymmetric shape makes it challenging to place the spar inside the skin such that its bending axis would coincide with the elastic axis of the wing and consequently, not induce any structural coupling. On the other hand the cross-shape section is more complicated to manufacture as it requires a bed during the machining to avoid bending. Yet, the positioning in the wing is easy due to its symmetrical shape, which is the reason why the cross-shape section was chosen. Based on the maximum desired weight of the spar the following constraints were applied to the optimisation procedure:

$$
\begin{array}{r}
0.001 m<b<0.14 m \\
0.001 m<c<0.13 m \\
b>c+0.005
\end{array}
$$




\begin{tabular}{ccc}
\hline & Target Model & Spar Model \\
\hline Mode 1 & $1^{\text {st }}$ Bending - 2.76 Hz & $1^{\text {st }}$ Bending - 5.6 Hz \\
Mode 2 & $2^{\text {nd }}$ Bending - 13.78 Hz & $1^{\text {st }}$ Lagging - 28.26 Hz \\
Mode 3 & $1^{\text {st }}$ Lagging - 13.90 Hz & $2^{\text {nd }}$ Bending - 32.5 Hz \\
Mode 4 & $1^{\text {st }}$ Torsion - 24.26 Hz & $1^{\text {st }}$ Torsion - 66.07 Hz \\
\hline Total Mass & $3.42 \mathrm{~kg}$ & $0.65 \mathrm{~kg}$
\end{tabular}

Table 4 Dynamic frequency of the target sub-scale model and the spar model

From the obtained second moment of area $I_{x x}$ and $I_{z z}$ the ratio $\frac{\left[E I_{x x}\right]^{\text {spar }}}{\left[E I_{x x}\right]^{K}}$ and $\frac{\left[E I_{z z}\right]^{\text {spar }}}{\left[E I_{z z}\right]^{K}}$ resulted in a value of 1 which proved that the stiffness terms were matched correctly by the optimiser. The CAD model of the final spar design is presented in Fig 5. The figure shows that in order to match the stiffness, the cross section of the spar was varied from the middle part towards the tip.

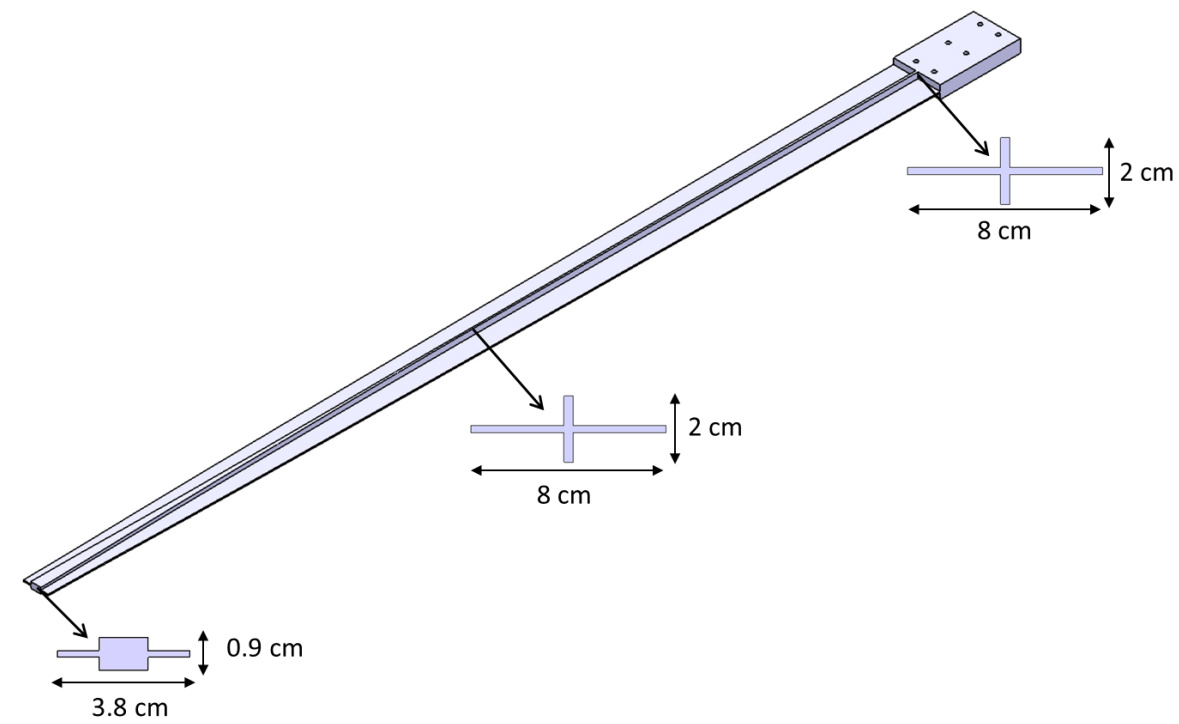

Fig. 5 CATIA CAD of the final spar with cross section.

Based on the optimisation results a Nastran model using PBeam elements was developed to obtain the theoretical dynamics of the spar. As the half-wing design was calculated from the center of fuselage, a comparable length of the sub-scale wing was also considered. The first three nodes in all DoF were constrained which was taken to design the clamp for ground/wind tunnel testing. It should be mentioned that the total mass of the spar was expected to be around $0.65 \mathrm{~kg}$ which is less than $25 \%$ of the total target weight.

The dynamic response of the spar model was analysed based on the Nastran solver SOL103. The comparison of the target sub scale model and the spar design mode frequency is presented in Table 4 . Due to the total mass of the spar which resulted in a quarter of the weight of the target model, higher structural frequencies are expected. Overall, the structural frequencies were almost two times higher than the target frequencies, which is expected to be lowered once the skin is attached and more mass is added.

\section{Skin Design}

As mentioned in the previous subsection, the skin was designed mainly to provide the aerodynamic shape while at the same time allowing enough flexibility to bend without any buckling issues, and transferring the load to the spar. A thin flexible pod was printed in between two rigid pods to ensure the flexibility of the wing under load. The skin was printed with the shape of NACA 23015, and its modular design was divided into four sections. This was based on the 
previous experience[15] to mitigate costs due to damage and to be able to design specific section for specific tests, such as added wingtip devices. The skin is designed to be printed modularly in span direction and connected using dowels. The wing is also provided with windows placed at the bottom to access pillars, spar, and instrumentation.

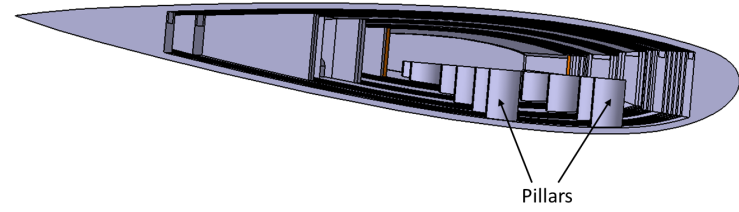

(a) Cross section cut along the chord line

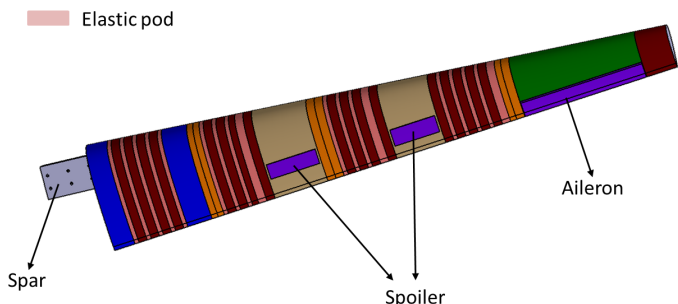

(b) CATIA CAD design of the wing. The small pink stripes represented the elastic pod.

Fig. 6 The skin design of the sub-scale model

The thickness of the wing plays an important role to the total weight of the wing. It was designed to have a thickness of $2 \mathrm{~mm}$. The leading and trailing edge of the wing were printed as full to reinforce the aerodynamic profile, especially on the trailing edge. Distributed pillars were designed to attach the skin to the spar (see Fig 6a), while also ensures aerodynamic load transfer. As a passive flutter suppression mechanism, a pocket was designed at the tip to locate additional mass.

The top view of the skin CATIA CAD model is shown in Fig 6billustrating that the elastic and rigid pods are designed with different lengths. The length of the flexible pod is always constant at $1 \mathrm{~cm}$, while the length of the rigid pod depends on the span wise location, considering the following: 1) The area where control surfaces are placed is supposed to be rigid to ensure the effectiveness of the control surface. Thus, at the position of the control surfaces, the skin was printed as a long continuous rigid pod. This is designed so that the first four target mode shapes are not affected. 2) The wing was designed to have windows for accessibility. These windows were distributed along the wingspan, which needed to be placed on the rigid pod.

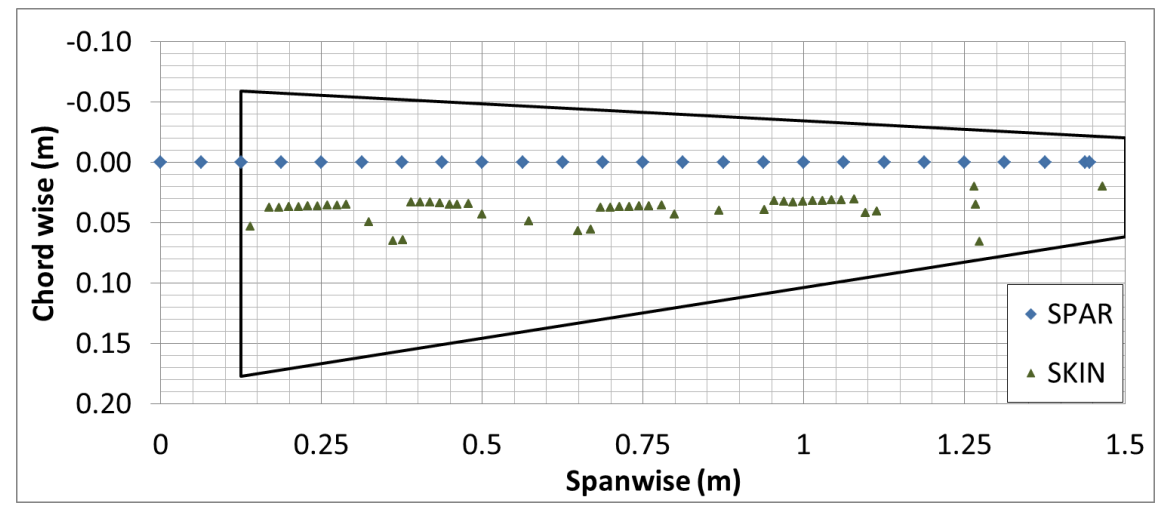

Fig. 7 The position of the center of gravity of the skin and spar

Based on the CAD model, the location of the centre of gravity (CoG), the mass and the mass moment of inertia properties of the skin at each section was calculated. The skin was modelled as a lumped mass in addition of the already developed Nastran model (see Fig.77). The target model was designed such that the location of the lumped mass was as close as possible at the position of the spar, which is around $25 \%$ chord. In contrary, the CoG of the skin was located more towards the trailing edge, at around $40 \%$ chord. The total weight of the skin was expected to be around $1.5 \mathrm{~kg}$, which makes the total sub-scale wing as $2.18 \mathrm{~kg}$ (target total mass $3.42 \mathrm{~kg}$ ). 
The reason why the mass of the skin and spar still does not match with the target weight is to allow space for added mass due to joints, instrumentation system, as well as servo actuator. On top of that, the added mass needs to be distributed along the wing in such a way to match the frequency and mode shape of the target model.

\begin{tabular}{ccc}
\hline & Target Model & Spar-and-Skin Model \\
\hline Mode 1 & $1^{\text {st }}$ Bending - 2.76 Hz & $1^{\text {st }}$ Bending - 3.1 Hz \\
Mode 2 & $2^{\text {nd }}$ Bending - 13.78 Hz & $1^{\text {st }}$ Torsion - 8.06 Hz \\
Mode 3 & $1^{\text {st }}$ Lagging - $13.90 \mathrm{~Hz}$ & $1^{\text {st }}$ Lagging - $15.8 \mathrm{~Hz}$ \\
Mode 4 & $1^{\text {st }}$ Torsion - 24.26 Hz & $2^{\text {nd }}$ Bending - $16.3 \mathrm{~Hz}$ \\
\hline Total Mass & $3.42 \mathrm{~kg}$ & $2.18 \mathrm{~kg}$
\end{tabular}

Table 5 Dynamic frequency of the target sub-scale model and the spar-and-skin model

The dynamic response of the spar with skin model was analysed using Nastran and is presented in Table 5. As expected, the added mass shifted the dynamic response towards a lower frequency. However, due to the centre of gravity location, as well as the mass moment of inertia distribution, the order of the modal response of the target and spar-and-skin model was changed, except for the $1^{\text {st }}$ bending mode. The higher mass moment of inertia along the chord is affected by the location of the CoG, so that the skin has a higher mass moment of inertia along the chord (Iyy) (Fig 8b). Higher Iyy affected the torsional mode so that it moved towards a lower frequency. Although change of a mode shape order was evident, the $1^{\text {st }}$ lagging and $2^{\text {nd }}$ bending were around the expected frequency. It should be noted that the mass of the spar-and-skin model still differ from the total targeted mass, resulting in a higher structural frequency of the spar-and-skin model compared to the frequency. Therefore, added mass was placed to be able to match the target structural response.

\section{Wind Tunnel Model}

As aforementioned, the skin-and-spar configuration has less mass compared to the total target mass, and at the same time has higher Iyy value (see Fig 8). The consequence of a higher Iyy value is that the torsional mode appears at a much lower frequency and before the $2^{\text {nd }}$ bending mode as expected from the target model. Ideally, the sub-scale model needs to represent the order of the mode shape similarly as the full-scale model. However, adding more mass will only shift the torsional mode into much lower frequency rather than swapped it with the other structural mode. The only possible way to swap the mode is by adding more torsional rigidity, which means changing the spar configuration. Thus, compromises need to be taken which means simplify the requirements of the sub-scale model to only matched the first structural mode and frequency and to have a flutter speed more than $60 \mathrm{~m} / \mathrm{s}$ inside the wind tunnel environment.

As this paper is aimed as a learning process for designing a sub-scale model at the conceptual design stage, an iteration of updating the total target weight by $20 \%$ is conducted. This brings the total target weight of $4.27 \mathrm{~kg}$ instead of $3.42 \mathrm{~kg}$, and have a lower frequency response as presented in Table 6 as target model ver.2. This iteration is needed to ensure enough separation of the $1^{\text {st }}$ bending and $1^{\text {st }}$ torsion mode, which leads to a higher flutter speed for a safer wind tunnel experiment.

Fig.8 presents the comparison of the mass and Iyy distribution of the sub-scale wing along the span location. This value was a simplification of the mass matrix produced by Nastran. The blue line represents the total mass and Iyy expected at each grid, whereas the red line represents the mass and Iyy of the spar-and-skin configuration. It shows that the spar-and-skin configuration did not match the overall target mass distribution, but in contrary almost exceeded the targeted Iyy distribution. Especially at grid point 21, which represents the location of aileron CoG.

In order to match the structural response efficiently, an optimisation routine is needed. Nevertheless, a first iteration, was chosen in which the mass and Iyy distribution has to be matched as close as possible with the target values. The matching of mass and Iyy value was done by calculating the lumped mass to be added and define its location around the 
skin in the chord wise direction(x) for each grid as follows :

$$
\begin{aligned}
& \Delta m_{i}=m_{i}^{t}-m_{i}^{s} \\
& \Delta I y y_{i}=I y y_{i}^{t}-I y y_{i}^{s} \\
& \text { if } \quad \Delta I y y_{i}<0, \quad x_{i}=0 \\
& \Delta I y y_{i}>0, \quad x_{i}=\sqrt{\frac{\Delta I y y_{i}}{\Delta m_{i}}}
\end{aligned}
$$

in which $m_{i}^{t}, m_{i}^{s}$ is the target mass and spar-and-skin mass at grid $i$, while $I y y_{i}^{t}, I y y_{i}^{s}$ is the mass moment of inertia at grid $i$.The value $x$ is the position in chord wise direction from $25 \%$ chord, in which negative represents leading edge direction and positive represents trailing edge direction. The position of the lumped mass is also calculated by considering the thickness of the skin without changing the aerodynamic shape.

\begin{tabular}{cccc}
\hline & Target Model & Target Model-Ver.2 & Wind Tunnel Model \\
\hline Mode 1 & $1^{\text {st }}$ Bending - 2.76 Hz & $1^{\text {st }}$ Bending $-2.5 \mathrm{~Hz}$ & $1^{\text {st }}$ Bending - 2.6 Hz \\
Mode 2 & $2^{\text {nd }}$ Bending - 13.78 Hz & $2^{\text {nd }}$ Bending - 12.34 Hz & $1^{\text {st }}$ Torsion - 7.65 Hz \\
Mode 3 & $1^{\text {st }}$ Lagging - $13.90 \mathrm{~Hz}$ & $1^{\text {st }}$ Lagging - $12.45 \mathrm{~Hz}$ & $1^{\text {st }}$ Coupled - 13.10 Hz \\
Mode 4 & $1^{\text {st }}$ Torsion - 24.26 Hz & $1^{\text {st }}$ Torsion $-23.56 \mathrm{~Hz}$ & $2^{\text {nd }}$ Coupled - 13.35 Hz \\
\hline Total Mass & $3.42 \mathrm{~kg}$ & $4.27 \mathrm{~kg}$ & $4.27 \mathrm{~kg}$ \\
\hline
\end{tabular}

Table 6 Structural frequency of the target, updated target sub-scale model, and the wind tunnel model

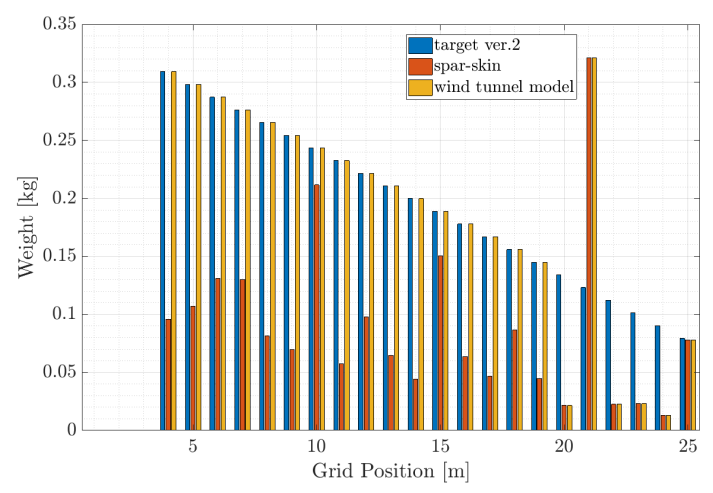

(a) Mass Comparison

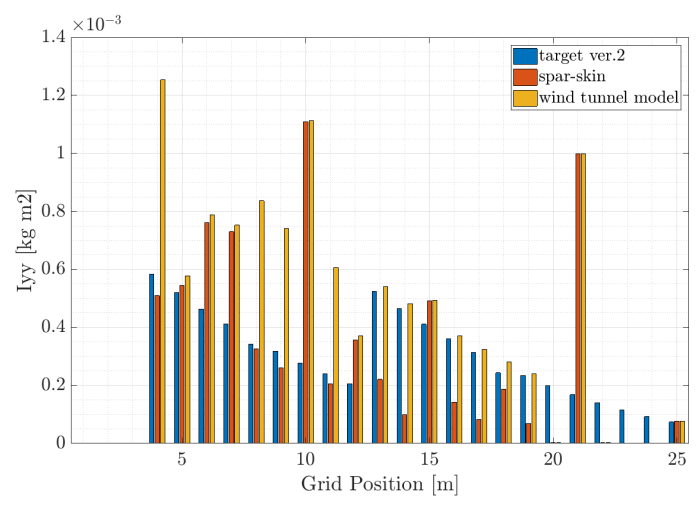

(b) Iyy Comparison

Fig. 8 Mass and Iyy matching between target sub-scale model, spar-and-skin configuration, and wind tunnel model

Once again Nastran is used to model these lumped masses and analyse the structural dynamics of the wind tunnel model (see Fig 8. The structural mode comparison is given in Table 6 , and shows that the $1^{\text {st }}$ Bending mode is only $4 \%$ higher compared to the target mode (ver 2). Further results exhibit by calculate flutter modes using Nastran SOL 145 is presented in Fig 9. All aeroelastic modes are having negative damping up until $70 \mathrm{~m} / \mathrm{s}$, which indicates that the flutter speed is higher than the maximum wind tunnel speed $(50 \mathrm{~m} / \mathrm{s})$.

\section{Experimental Results}

\section{A. Experimental Test Setup}

A ground vibration test (GVT) has been carried out by exciting the spar with the use of random-on-random (RoR) vibration control in a frequency range of $0.5 \mathrm{~Hz}$ to $100 \mathrm{~Hz}$. The spar was mounted to a rigid structure using the designed clamping fixture at the spar root. As shown in Fig $10 \mathrm{~b}$ the excitation was introduced to the spar structure via a stinger that was attached to the underside of the spar root. The structural dynamics were characterised by using five uni-axial 

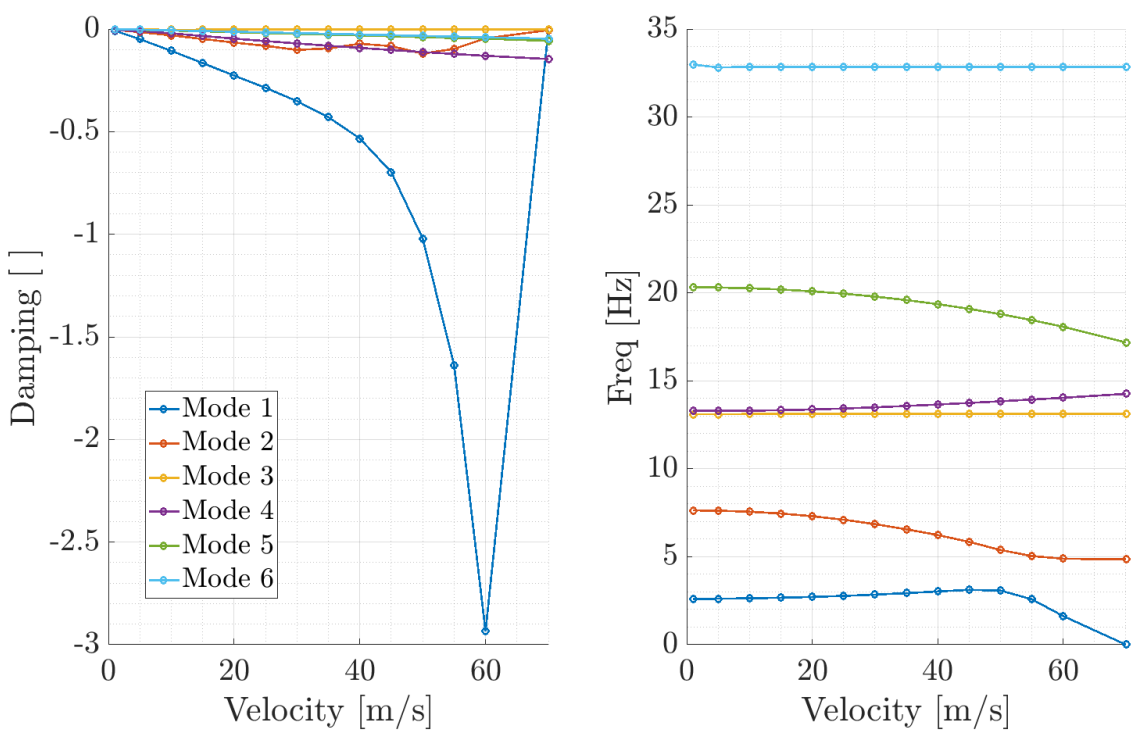

Fig. 9 Flutter Speed

accelerometers (see Fig $10 \mathrm{c}$. To ensure that the desired target modes are captured as accurately as possible a heuristic sensor placement approach was used. The idea of this methodology is to minimise the total error between theoretical and sensor mode shape. This was done by minimising the following cost function:

$$
J=\sqrt{\frac{1}{n} \sum_{i=1}^{m} \sum_{j=1}^{n}\left(\phi_{i j}-\hat{\phi_{i j}}\right)^{2}}
$$

where $\phi$ is the numerical mode shape, $\hat{\phi}$ is the sensor mode shape, $m$ is the number of target mode shapes to be considered, and $n$ is the number of nodal points. The benefit of this approach is that each mode shape is treated equally important ensuring that the target mode shapes can be identified during the experimental testing.

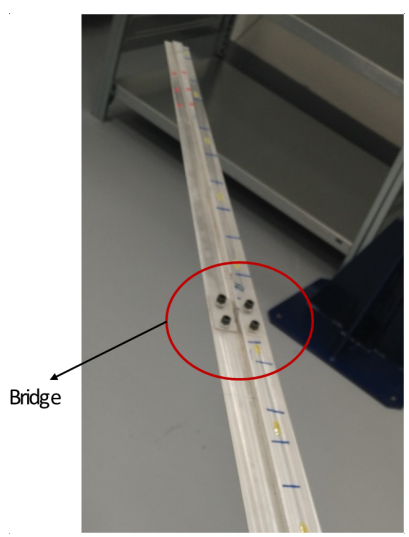

(a) Bridged spar

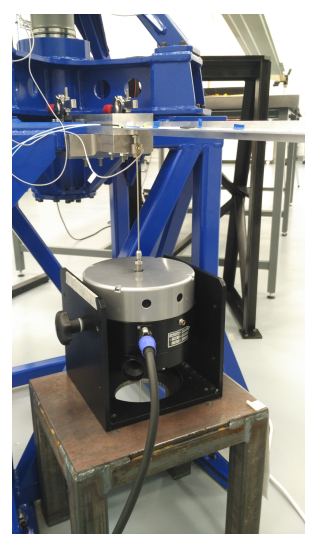

(b) Instrumentation set-up

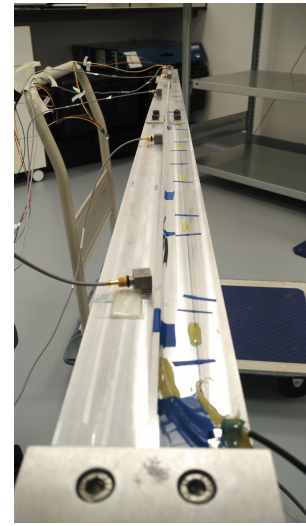

(c) Test bench

Fig. 10 Ground Vibration Test of spar configuration

\section{B. Experimental Validation: Spar Only Configuration}

As the total length of the spar is $1.45 \mathrm{~m}$ a compromise had to be made during the manufacturing process as it was difficult to machine the spar in one piece. Therefore the spar was separated in two equal halves for the manufacturing 


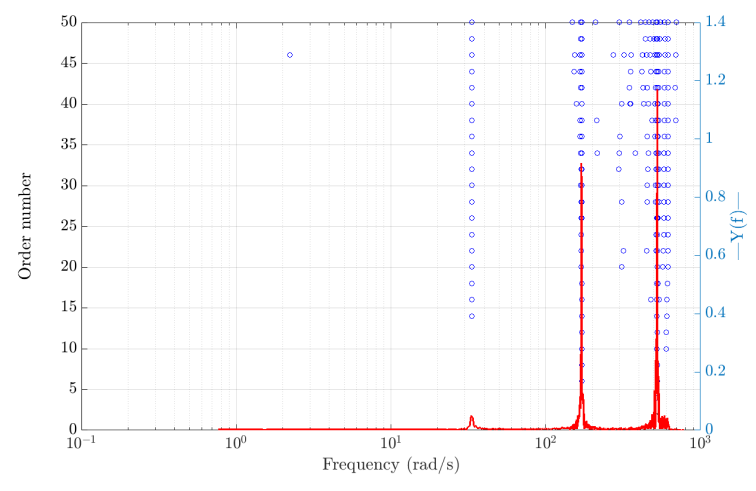

(a) Stabilisation Diagram

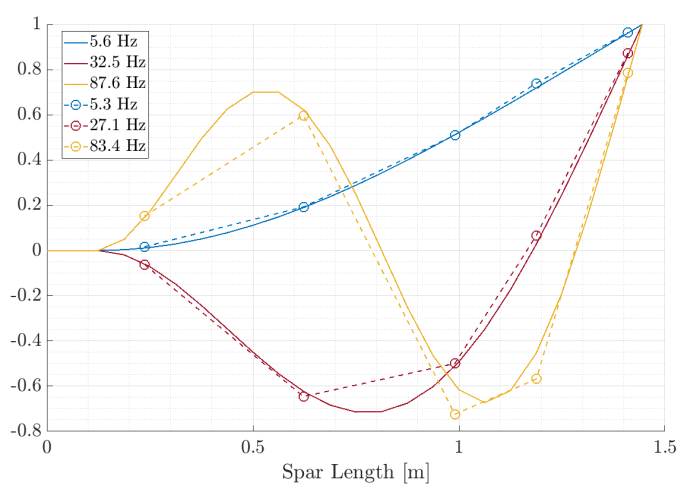

(b) Identified mode shape from GVT on the spar

Fig. 11 Spar only configuration GVT results

process and welded together afterwards to obtain a single spar. To ensure that the welding seam does not fatigue during the structural testing a bridge was fixed around the welding joint (see Fig 10a). This additional action resulted in updating the developed Nastran by modelling the additional support as a lumped mass. Results showed that the change in frequency, as well as mode shape is negligibly small.

As only uni-axial accelerometers are used, only the bending modes could be identified from the GVT test adopting subspace identification methods[22]. Results are presented in Table 7 while Fig 11 shows the stabilisation diagram and identified mode shapes.

After comparing the natural frequencies, it is essential to check how well the analytical and experimentally determined frequencies compare to the same physical mode. This can be achieved with the use of the MAC defined as follows:

$$
M A C=\frac{\left|\phi^{T} \phi_{X}\right|^{2}}{\left(\phi^{T} \phi\right)\left(\phi_{X}^{T} \phi_{X}\right)}
$$

where $\phi$ is the numerical mode shape and $\phi_{X}$ is the experimental mode shape. A value of MAC close to 1 indicates a correct pairing of the modes. According to Ewins [23] a MAC value between 0.9 - 1 is obtained for well-correlated modes and a value of 0.1 is an indication of uncorrelated modes.

\begin{tabular}{ccccc}
\hline & \multicolumn{2}{c}{ Spar Model } & \multicolumn{2}{c}{ Differences } \\
& Theoretical & Experimental & Freq. & MAC \\
\hline $1^{\text {st }}$ Bending & $5.57 \mathrm{~Hz}$ & $5.27 \mathrm{~Hz}$ & $5 \%$ & 0.999 \\
$2^{\text {nd }}$ Bending & $31.09 \mathrm{~Hz}$ & $27.12 \mathrm{~Hz}$ & $12 \%$ & 0.993 \\
$3^{r d}$ Bending & $87.15 \mathrm{~Hz}$ & $83.39 \mathrm{~Hz}$ & $4 \%$ & 0.967 \\
\hline
\end{tabular}

Table 7 Comparison of numerical spar and manufactured spar frequency

\section{Conclusion and Further Work}

This paper presents a conceptual design of a half-wing aircraft, followed by scaling law methodology, the definition and manufacturing process of the sub-scale model. This work is part of the BEAm Reduction and Dynamic Scaling (BEARDS ) programme, which aimed to develop a methodology to design, manufacture and testing a dynamically scaled High Aspect Ratio (HAR) wings for use in Cranfield's 8" x 6" tunnels[15]. Such a sub-scale model is important to observe the dynamic behaviour of HAR wings, and to rule out any unwanted aeroelastic coupling at an early design stage. This paper emphasises on the methodology being used to manufacture the sub-scale model, which are the combination of spar design to represent the stiffness properties of the whole wing, PolyJet printed wing to hold the aerodynamic profile, and added mass to ensure the dynamic similitude of the sub-scale model.

There are several lesson-learnt that can be taken from BEARDS sub-scale model design process: 
1) For a relatively low-cost spar model, a compromise had to be made by manufacturing the spar in two pieces. These two pieces were put together through welding and bridging. Both weld and bridge have a negligible impact on the dynamic behaviour of the spar model, as the added weight is less than $1 \%$ of the whole spar.

2) Using the PolyJet technology to print the skin adds significant mass to the total wing design, which significantly affected the torsional dynamics of the sub-scale model.

3) The aileron was printed as a full section, which introduces a higher mass moment of inertia value. A second iteration considering lighter material is needed for the future.

4) The sub-scale model is susceptible to added mass, and its position, a detailed sensor, actuator, and servo position needs to considered before placing the added mass.

5) the full-scale conceptual design of the wing is too idealistic and gives small room for adding mass. Therefore, iteration loop is needed.

As a result of the lesson learnt and as a measure of compromise due to physical limitation during the manufacturing process, BEARDS workflow allows the feedback loop of updating the full-scale model based on the experimental results of the sub-scale model. As further work, an updated full-scale model will be designed by considering more detailed wing design. Furthermore, GVT testing needs to be conducted for each stage of iteration. Further work also needs to address the dynamic aeroelastic response of the sub-scale model utilising BEaRDS ${ }^{T M}$, as well as mass placement on the sub-scale model followed by wind tunnel testing. The observed dynamic behaviour of the sub-scale model can be used to determine the design of the aircraft and used to mature the design of a high aspect ratio wing.

\section{Acknowledgments}

This work is supported and developed in collaboration with Airbus Group, Innovate UK and the Aerospace Technology Institute (UK ATI). The authors would also like to acknowledge the support of the Indonesia Endowment Fund for Education (Lembaga Pengelola Dana Pendidikan - LPDP). The authors also wants to acknowledge MarieEmanuelle Bondo for her help in building the CAD model, as well as Martin Carrizales, and Gaetan Dussart for their contribution as the part of BEARDS team.

[1] Chambers, J., Modeling Flight, NASA, 2010.

\section{References}

[2] Kraft, E. M., “After 40 Years Why Hasn’t the Computer Replaced the Wind Tunnel?” ITEA Journal 2010, , No. 31, 2010, pp. 329-346.

[3] Bradley, M., and Droney, C., "Subsonic Ultra Green Aircraft Research Phase II: N+4 Advanced Concept Development," Tech. rep., NASA, 2012.

[4] Ryan, J., Bosworth, J., and Burken, J., "Current and Future Research in Active Control of Lightweight, Flexible Structures Using the X-56 Aircraft,” AIAA SciTech Forum, National Harbor, Maryland, 2014. doi:10.2514/6.2018-1014.

[5] Andrews, S., "Modelling and simulation of flexible aircraft: handling qualities with active load control," Ph.D. thesis, Cranfield University, School of Engineering, 2011.

[6] Dussart, G., Yusuf, S., and Lone, M., "Effect of Wingtip Morphing on the Roll Mode of a Flexible Aircraft," AIAA Agile Wing Interactions, AIAA SciTech Forum, Orlando, Florida, 2018. doi:10.2514/6.2018-1683.

[7] Wan, Z., and Cesnik, C., "Geometrically Nonlinear Aeroelastic Scaling for Very Flexible Aircraft," AIAA Journal, Vol. 52, No. 10, 2014, pp. 2251-2260. doi:10.2514/1.J052855.

[8] French, M., and Eastep, F., “Aeroelastic Model Design Using Parameter Identification,” Journal of Aircraft, Vol. 33, No. 1, 1996, pp. 198-202. doi:10.2514/3.46922.

[9] Ricciardi, A. P., Eger, C. A. G., Canfield, R. A., and Patil, M. J., "Nonlinear Aeroelastic-Scaled-Model Optimization Using Equivalent Static Loads,” Journal of Aircraft, Vol. 51, No. 6, 2014, pp. 1842-1851. doi:10.2514/1.C032539.

[10] Ricciardi, A. P., Canfield, R. A., Patil, M. J., and Lindsley, N., “Nonlinear Aeroelastic Scaled-Model Design,” Journal of Aircraft, Vol. 53, No. 1, 2016, pp. 20-32. doi:10.2514/1.C033171.

[11] Bond, V. L., Canfield, R. A., Suleman, A., and Blair, M., “Aeroelastic Scaling of a Joined Wing for Nonlinear Geometric Stiffness,” AIAA Journal, Vol. 50, No. 3, 2012, pp. 513-522. doi:10.2514/1.41139. 
[12] Spada, C., Afonso, F., Lau, F., and Suleman, A., "Nonlinear Aeroelastic Scaling of High Aspect-Ratio Wings," Journal of Aerospace Science and Technology, Vol. 63, 2017, pp. 363-371. doi:10.1016/j.ast.2017.01.010.

[13] Heeg, J., Spain, C., and Rivera, J., "Wind Tunnel to Atmospheric Mapping for Static Aeroelastic Scaling," AIAA Structures, Structural Dynamics \& Material Conferences, Palm Springs, California, 2004.

[14] Zhu, W., Li, D., Zhang, Z., Ren, K., Zhao, X., Yang, D., Zhang, W., Sun, Y., and Tang, Y., "Design and Fabrication of Stereolithography-based Aeroelastic Wing Models," Rapid Prototyping Journal, , No. 17/4, 2011, pp. 298-307. doi: $10.1108 / 13552541111138423$.

[15] Pontillo, A., Hayes, D., Dussart, G., Lopez, G., Carrizalez, M., Yusuf, S., and Lone, M., "Flexible High Aspect Ratio Wing: Low Cost Experimental Model and Computational Framework," AIAA Atmospheric Flight Mechanics Conference, AIAA SciTech Forum, Orlando, Florida, 2018. doi:10.2514/6.2018-1014.

[16] Hayes, D., Pontillo, A., Yusuf, S., Lone, M., and Whidborne, J., "High Aspect Ratio Wing Design Using the Minimum Exergy Destruction Principle," AIAA Atmospheric Flight Mechanics Conference, AIAA SciTech Forum, 2019.

[17] Torenbeek, E., "Development and Application of a Comprehensive, Design-sensitive Weight Prediction Method for Wing Structures of Transport Category Aircraft,” Tech. rep., Delft University of Technology, 1992.

[18] Timoshenko, S., and Goodier, J., Theory of elasticity, McGraw-Hill, 3rd ed., 1970.

[19] Duncan, W., Physical Similarity and Dimensional Analysis: An Elementary Treatise, Edward Arnlod \& Co, London, 1953.

[20] “Cranfield University 8x6 Wind Tunnel,", Accessed: 2018-12-10. URL https://www.cranfield.ac.uk/facilities/ $8 \times 6$-wind-tunnel.

[21] Przemieniecki, J., Theory of Matrix Structural Analysis, Dover, 1985.

[22] Van Overschee, P., and De Moor, B., Subspace Identification for Linear Systems, Kluwer Academic Publishers, Dordrecht, The Netherlands, 1996.

[23] Ewins, D., Modal Testing: Theory, Practice and Application, Research Studies Press LTD, Hertfordshire, England, 2000. 


\section{Cranfield University}

$2019-12-31$

\section{Aeroelastic scaling for flexible high aspect ratio wings}

Yusuf, Sezsy

AIAA

Yusuf SY, Pontillo A, Weber S, et al., (2019) Aeroelastic scaling for flexible high aspect ratio wings, AIAA Scitech 2019 Forum, 7-11 January, San Diego, CA, USA

https://doi.org/10.2514/6.2019-1594

Downloaded from Cranfield Library Services E-Repository 